\title{
A MATTER OF FACTOR: A PROPOSED METHOD FOR IDENTIFYING FACTORS THAT INFLUENCE DESIGN EFFORT LEVELS IN PRODUCT DESIGN
}

\author{
Holliman, Alexander 'Freddie'; Thomson, Avril; Hird, Abigail; Wilson, Nicky \\ Department of Design Manufacture and Engineering Management, University of Strathclyde
}

\begin{abstract}
Design effort, the amount of time required to complete a project or task (Salam et al., 2009; Salam and Bhuiyan, 2016), is a required resource for any design project which can be influenced by a number of factors. Estimating design effort is a significant challenge that can be mitigated through an understanding of these influential factors. This understanding is held as tacit knowledge by experts, earned through experience; yet, although these factors vary in type and impact, understanding their details can provide insight and improve future estimations. Some previous methods to estimate design effort identify these factors, either from: expert opinion, or historical data analysis with each approach has advantages and disadvantages.

This paper is comprised of three parts:

A review of published methods and tools for estimating product design effort and whether they consider and identify influential factors; an analysis of possible trends in the identification of factors influencing product design project length; and a new method for identifying the influential factors of product design project length.
\end{abstract}

Keywords: Design management, Knowledge management, Project management, Design Effort Estimation

Contact:

Holliman, Alexander 'Freddie'

University of Strathclyde

Department of Design Manufacture and Engineering Management

United Kingdom

alexander.holliman@strath.ac.uk

Cite this article: Holliman, A. 'Freddie'., Thomson, A., Hird, A., Wilson, N. (2019) 'A Matter of Factor: A Proposed Method for Identifying Factors that Influence Design Effort Levels in Product Design', in Proceedings of the 22nd International Conference on Engineering Design (ICED19), Delft, The Netherlands, 5-8 August 2019. DOI:10.1017/ dsi.2019.108 


\section{INTRODUCTION}

Design, as an activity, can be considered as the core of a range of creative roles (Harfield, 2007) therefore any discussion on the planning of design activities will benefit design practitioners and theorists from many disciplines. The development of a clear, detailed plan is the first stage of most design project processes (Jack, 2013) and is critical to a project's success, leading to the creation of a high quality product (O'Donovan et al., 2005). Yet studies have shown that even world-leading companies possess little understanding of design planning (O'Donovan et al., 2005), leading to problems with their planning processes. This is, in part, due to companies not analysing the cause of such problems in the planning process, leading to the resentment and blame of the project manager for a plan's lack of success (Eckert and Clarkson, 2010). It is clear that no two design projects the same, and also that the design process itself is inherently uncertain (Dong et al., 2014; Eckert and Clarkson, 2010; Pich et al., 2002), therefore the challenge in estimating design effort to complete a project is a particularly difficult one (Salam and Bhuiyan, 2016).

\subsection{Quantifying design resource}

The universal resource for any design project is a function of time, commonly referred to as Design Effort. Measured in person-hours or similar, is the amount of time required to complete a project, or a task (Salam et al., 2009; Salam and Bhuiyan, 2016). It is common to any project and once it has been used, it is not possible to create any more. Managers will estimate the design effort required for project phase; This estimate will not only inform the assignment of project staff, but also the quotation of project cost for the client, as project cost and project length are intrinsically linked (Bashir and Thomson, 2001a; Hellenbrand et al., 2010).

\subsection{Influential factors}

Effort estimations for design projects are typically based on the planner's perceptions of the factors which influence project length, the Influential Factors (IF's). These perceptions come from a foundational understanding of design developed through experience. Such IF's can range from the commonly considered factor of perceived complexity of the product (Griffin, 1997; De Lessio, 2016; O'Donovan et al., 2005), to the "gut feeling" a design agency has of a client has of their client (Holliman et al., 2018). By understanding and sharing their understanding and perceptions on such IF's, design teams can gain a level of insight which can help improve project management decisions. Understanding which IF's are most influential on project length results in improvements in project time estimation and in-turn, improve the organisational understanding of product development in general. However, such improvement is predicated on understanding which IF's are most influential. This paper will explore the methods developed to identify design project IF's covered in literature and propose a new method to aid designers identify IF's that is currently in development.

This paper is comprised of three parts:

1. A review of published methods and tools for estimating product design effort, specifically examining the means by which they identify the IF's of design effort for product design projects.

2. An analysis of possible trends in the identification of design effort level influencing factors in product design projects

3. A proposed new method for identifying design effort level influencing factors in product design projects.

\section{A REVIEW OF METHODS}

For this study, thirty-five papers were identified where the estimation of product design project time as either the focus of the method covered, or as a function of a broader method. After review, sixteen of these papers were either identified as being generic project management methods, and therefore not specifically tailored to the estimation of design effort; or were identified as being an abstracted theory, with no specific links to product design. The remaining nineteen papers are varied in their scope, from specific areas of product design such as the design of manufacturing tooling, to more generic product design project time estimation. There were papers, such as Jacome \& Lapinskii (1997), that propose tools for project cost estimation, where the authors suggest that the cost of a design project in intrinsically linked to its length, and therefore the estimation of project length is a key activity for their 
method. Papers were categorised into six ways: papers that identified influential factors as part of their process, either through participant involvement or data analysis; Papers that build upon the theoretical existing work (either from design fields, or from otherwise), and papers whose methods do not include factors at all. These categorisations are outlined in Table 1.

Table 1. Design effort in product design project estimation methods that consider influential factors

\begin{tabular}{|c|c|c|c|c|c|c|}
\hline & 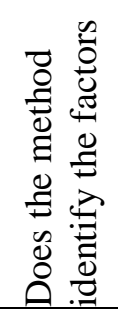 & 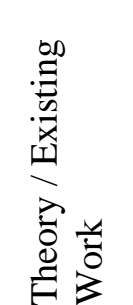 & 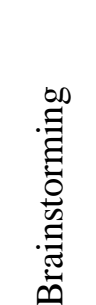 & 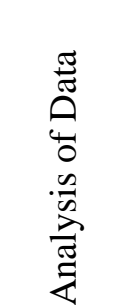 & 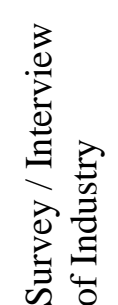 & 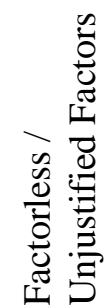 \\
\hline Bashir \& Thomson (2004) & - & & - & & & \\
\hline Andersson et al. (1998) & - & & & & - & \\
\hline Shang \& Yan (2016) & • & & & & - & \\
\hline Benedetto et al. (2017) & - & & & & - & \\
\hline Griffin (1993) & • & - & & - & & \\
\hline Yan \& Shang (2015) & • & & & - & & \\
\hline Hellenbrand et al. (2010) & • & & & - & & \\
\hline Cho \& Eppinger (2005) & • & & & - & & \\
\hline Bashir \& Thomson (2001a) & & - & & & & \\
\hline Bashir \& Thomson (2001b) & & - & & & & \\
\hline Xu \& Yan (2006) & & - & & & & \\
\hline Yan \& Xu (2007) & & - & & & & \\
\hline Salam et al. (2009) & & - & & & & \\
\hline Pollmanns et al. (2013) & & - & & & & \\
\hline Wang et al. (2015) & & - & & & & \\
\hline Eppinger et al. (1997) & •* & & & - & & \\
\hline Jacome \& Lapinskii (1997) & & & & & & - \\
\hline \multirow[t]{2}{*}{ Yan et al. (2010) } & & & & & & - \\
\hline & $\begin{array}{c}8 \\
44.4 \%\end{array}$ & $\begin{array}{c}8 \\
44.4 \%\end{array}$ & $\begin{array}{c}1 \\
5.6 \%\end{array}$ & $\begin{array}{c}5 \\
27.8 \%\end{array}$ & $\begin{array}{c}3 \\
16.7 \%\end{array}$ & $\begin{array}{c}2 \\
11.1 \%\end{array}$ \\
\hline
\end{tabular}

\subsection{Methods that identify factors}

Of the methods reviewed, eight (44.4\%) included IF identification in their processes. Four identify IF's through statistical analysis, such as Yan \& Shang (2015). A further four methods identify IF's by engaging with experts through either brainstorming activities, or through surveys/interviews.

A method for obtaining product development cycle time performance baselines through the application of regression analysis on historical data is proposed by Griffin (1993). Uniquely, this method identifies IF's which affect cycle time from both a literature review and existing study data analysis. For Andersson, Pohl \& Eppinger (1998), IF's are gathered through worker interviews, this is an extension to the signal flow graphs method, outlined by Eppinger et al. (1997). Industry workers also provide details of IF's and their relationships for the method described by Bashir \& Thomson (2004) through brainstorming. This contributes to parametric model development tailored for specific companies.

Data analysis is used to identify IF's in four papers covered in this review. The method by Cho \& Eppinger (2005) is a variant of the design structure matrix (DSM) (Steward, 1981) tool identifies system variables (factors) and relationships, modelling information transfer patterns, resources conflicts overlapping and sequential iterations; and task concurrency. The model created considers that the system variables can evolve over time.

Data analysis IF identification methods commonly involve regression analysis. Some, like Hellenbrand et al. (2010) use regression analysis to identify influential factors to train a Monte-Carlo simulation for product development cost estimation. Developed to overcome the uncertainty found at the start of a project, this method focuses on project cost, although the authors identify the strong correlation between 
cost and effort (time). Yang \& Shang (2015) also identify factors through data analysis to develop a forecasting tool using a support vector regression with probabilistic constraints (PC-SVR).

Questionnaires, interviews and brainstorming are common approaches to identifying IF's from the perspective of experts in industry. Shang \& Yan (2016) suggest a method which has been developed to overcome small samples and heteroscedastic noise found in design time forecasting. This method identifies IF's (referred to as time factors and engineering characteristics) through self-administered questionnaires, based on a survey-based methodology.

In-depth interviews are the source of information on IF's in the method discussed by Benedetto et al. (2018), taking a work breakdown structure (WBS) and producing a project network standard to create a guide for the successful completion of design activities. Their study uses data from 13 design professionals, discussing what influences the design project quotation process and identifying four dimensions (factors) influential to the design process.

\subsection{Finding factors in the literature}

Of the methods reviewed, eight methods (44.4\%) based their assumptions of IF's on pre-existing research or models; or synthesise a list from a literature review.

The method proposed by Bashir \& Thomson (2001b) takes evaluations of: past project productivity and the factors which affected that productivity, applying them to an eigenvector approach (based Saaty (1980)). Based on a literature review, Bashir \& Thomson propose a shortlist of project length IF's, and although each are prescribed into the method, they acknowledge that each design team the method is applied to may result in different factors from said shortlist becoming the most influential. In that way, it is neither a method which explicitly identifies IF's, like those in the previous section, but also not a method which exclusively uses a de facto list of pre-determined factors. The widelycited paper by Bashir \& Thomson (2001a) proposes two models for estimating design effort and time. Both methods use historical data with the jackknife resampling method and regression analysis to develop estimation models. Both models consider product complexity to be a major contributing factor. The other factor suggested is that of Severity of requirements.

Xu \& Yan (2006) developed a "Fuzzy measurable house of quality (FM-HOQ)" by taking the House of Quality from the Quality Function Deployment (QFD) and applying a fuzzy neural network (FNN) to the process. The researchers take factors from literature to set the parameters of the FNN, taking historical data to train the FNN in order to identify relationships between factors, etc.

Another Fuzzy-based approach is proposed by Yan \& Xu (2007). This method uses a fuzzy nu-support vector machine (Fnu-SVM) to forecast design efforts. First introduced by Vapnik et al (1995), SVM is a supervised learning model designed for classification and regression analysis. Yan \& Xu use an SVM as the basis for their own model, building on other research findings and literature to infer relationships for effort estimation. The authors cite another paper when referring to IF's (or input variables, as referred to in the paper) (Xu and Yan, 2004) when listing four types of input variables for a Fnu-SVM: product characteristics, design process, design condition, and design team.

An example of a method which is developed for a specific use case is proposed by Salam et al. (2009), for the design of aircraft engine compressors by Pratt \& Whitney to estimate design effort. Using a multiple linear regression model (MLRM) to facilitate a parametric modelling technique, the method considers three factors: type of design, degree of change, and experience of departmental personnel.

Pollmanns et al. (2013) propose a method of devolving an information model to evaluate design projects against a series of IF's (identified through a literature review) in order to develop design effort estimates. Such information models require historical data to establish relationships between stages, IF's, etc.

A tool for variant design time predictions is proposed by Wang et al. (2015), using a combination of the chaos particle swarm optimization (CPSO) and FNN. This is a theoretical method builds a FNN from the established relationships between product factors (this paper covers printer design, so all factors relate to the performance characteristics and features of a printer) with their influence weighting established by correlation degree. The authors do not specify the source of these printer factors, however in their own literature review, they discuss general factors which impact design project time. 


\subsection{Other factored methods}

\subsubsection{Factors without justification}

Two of the papers reviewed make use of factors, or some other term for factors, in their methods without justifying their use, making an assumption on their influence over project length.

Jacome \& Lapinskii (1997) refer to a Nonrecurring Engineering (NRE) project which they define in similar terms to a design project (based on the nonrecurring nature of design projects). They propose a method to produce an NRE project cost estimation tool to be used within the electronic product design industry. Like Hellenbrand et al. (2010), the authors draw a direct correlation between project cost and duration. This tool bases its estimates on the IF's: product size, product complexity and factors relating to productivity, although the source of these factors are not specified.

Zhi-gen \& Yan (2011) proposes a model for identifying relevant project parameters and predict time with those parameters. This is achieved through the use of Gaussian Margin Regression (GMR) analysis and is specifically developed when even a small data set is available. The factors used for the regression analysis are assumed without any literature-based justification discussed.

\subsection{Factorless methods}

\subsubsection{Participation factors}

Eppinger, Nukala \& Whitney (1997) propose a method for modelling the design process to be analysed using signal flow graphs. This model can also be used to calculate project duration distributions and predict significant project metrics, such as the expected mean and variance of lead time. Additionally, this model can provide insight into the iterative structure of the projects and the sensitivity of the lead time to the parameters of the model. This process requires the participation on the designers/engineers of the company that the model is intended for. This method does not explicitly identify IF's, instead identifying "participation factors", commonly used in linear system theory.

\subsubsection{The phenomena, not the factors}

Some methods cover similar phenomena to the effect of IF's on project length, but not specifically such factors. Smith \& Eppinger (1997) propose a method for developing a DSM-based extension model to estimate design project duration and to recommend coupled design task order to minimise project time. Using the pre-existing theories of DSM and Reward Markov Chains, data collected from a company's managers and engineers is analysed to determine the probability of task repetition. This method does not explicitly identify IF's, an understanding of the what effects the calculated probability is required.

Another study which does not consider IF's, as previously defined, is Yan et al. (2010), who proposes a method to reduce product development time based on the DSM (Steward, 1981) method. This method includes the observations of Krishnan et al. (1995) (upstream information evolution and downstream information change sensitivity) and Carrascosa et al. (1998) (extended concepts of change and impact probability). This method requires modelling the entire product development process, analysing relationships and establishing dynamic characteristics of information flow with statistical optimisation method Sequential Quadratic Programming (SQP) (Yuan and Sun, 1997). Using data gathered in other studies, this is a theoretical method which has not been tested, or validated, in industry. This method is designed for product development optimisation - specifically development time and cost.

\section{ANALYSIS OF FACTOR IDENTIFICATION WITHIN PRODUCT DESIGN PROJECT LENGTH ESTIMATION METHODS}

\subsection{Going to the source}

$42 \%$ of the design project estimation tool creation methods covered in this review identify project time IF's on a case-by-case basis; Finding the IF's each considered influential by each design group that undertake the method. Of these methods, half gather information directly from the practicing designers, engineers, managers, etc.; The other half gather their data through some form of statistical analysis. It is reasonable to assume that there are clear advantages to each method. Both, in their own way, process historical data to synthesise their conclusions on projects and factors.

Working with design industry professionals, it is possible to obtain a level of understanding afforded to those who have years of experience. It is this experience, and the earned tacit knowledge from past 
experiences that forms perceptions held around design projects and the IF's which influence them. Therefore, it is the perceptions of these IF's which informs the thought processes behind the creation of estimations, quotations, etc. for new projects (Serrat et al., 2013). Yet for all the lessons learned through experience and the wealth of knowledge accrued over a life in industry, estimates made by experts can still be affected by influences, such as bias (Bashir and Thomson, 1999). Therefore, it is reasonable to assume that, so too are the perceptions on project length IF's. Similarly, any discussion of factors may lead to disagreement between parties, leading to further impact on what factors are truly influential.

Conversely, the analysis of data through simple, or sophisticated means can highlight patterns in past project performance and uncover which IF's have influenced project length in the past. When considering facts, rather than opinion (albeit from experts), there is no opportunity for bias from these experts tainting the results. However, these statistical approaches require some basic understanding of IF's, or typically in these cases variables, in order to identify which are exerting influence. Therefore, such methods are dependent on the knowledge of the practitioner to program, train, etc. their analytical tools. Furthermore, such methods require accurate records of past projects, ideally in significant quantities to conduct a robust analysis. For many companies, such record keeping has not been possible. Additionally, such analysis tends to need sophisticated software, or at least a competency in analytical methods to perform such investigation; Neither may be accessible within the product design industry.

\subsection{The conclusions from other research}

$42 \%$ of the papers covered in this review discuss methods that base their assumptions of IF's on either a literature review, or from another study. This approach has the clear advantage of a rigorous foundation of peer-reviewed research. Yet, the reliance on past research has the potential of overlooking the possible changes in trends, attitudes or approaches to product design, as research takes time to be conducted, analysed and published. $84 \%$ of papers covered use IF's as the critical variables when estimating design effort. Clearly the identification and comprehension of IF's a critical part design effort estimation. Yet, only half of these papers ( $42 \%$ ) use some form of IF identification to inform their methods.

\section{A PROPOSED NEW METHOD FOR IDENTIFYING THE INFLUENTIAL FACTORS OF PRODUCT DESIGN PROJECT LENGTH}

This section discusses a proposed new method for the identification design effort level IF's in product design projects. As discussed in the previous section, there are distinct advantages to both engaging with designers, engineers, managers, etc. working in industry, and in the use of statistical analysis; when it comes to identifying IF's. Therefore, this proposed new method will utilise said advantages of each approach, while attempting to mitigate the potential disadvantages.

\subsection{Application of proposed method}

This proposed method is intended to be used with whole design teams, either of larger engineering companies, or ever member of a design agency. By working with an entire design team, from graduatelevel designer to Design Director, this method takes advantage of the unique experiences and knowledge that each team member has. By doing so at the same time, will allow team members to discuss and debate their perspectives, not only allowing for an exchange of perspectives, but also creating a comprehensive list of IF's. As such, this proposed method is intended to develop lists of IF's on a caseby-case basis. As such, although there is the potential for the same, or similar lists of IF's to be created by discrete design teams, this method will not create a de facto list of global IF's for design projects.

\subsection{Methodology}

Working with an entire design team, from graduate-level designer to Design Director, the multiworkshop-based approach takes three steps, with each step having their own sub-steps:

1. Develop an exhaustive list of factors considered to be most influential by a design team.

2. Create a shortlist of factors based on influence.

3. Establish a hypothetical minimum and maximum value for each factor.

4. Generate a series of hypothetical design projects.

5. Estimate the design effort required to complete each of the design projects.

6. Statistical analysis on participant estimates.

The rest of this section will describe this new method using an experiment as an example. 


\subsubsection{Develop an exhaustive list of factors considered to be most influential by a design team}

As a single group, the participants (design team) should conduct a group classic brainstorming activity. In which the participants should discuss all potential design effort level IF's, creating an exhaustive long list. This list can include specific factors, such as "material types", or as general factors as "perceived number of parts". Once this exhaustive list is created, these factors should be grouped together based on similarity, creating common over-arching factors (i.e. "number of parts" and "need for electronics to be included" could be combined, with other factors, to form "product complexity") to create a collated list of factors. Factors within each grouping can aid in the definition of each of the collated list factors.

\subsubsection{Create a shortlist of factors based on influence}

To create a shortlist, each participant should vote on which of the collated list of factors are most influential, selecting the top five and ranking them in order of perceived influence. This should be done individually to prevent the participants from influencing each other. (Pilot testing of this method found that once a manager publically cast their vote, the other team members felt they needed to "agree with the boss".) The factors receiving the highest votes are then considered the shortlist of most influential by the group.

\subsubsection{Establish a hypothetical minimum and maximum value for each factor}

In another group discussion, each of shortlist factors are then assigned a hypothetical maximum and minimum value, defining their scale of measurement (i.e. for "number of parts" setting the minimum as " 1 " and the maximum as " $30+$ " by the participating design team). The factors and level values are used to inform the experimental design of the next stage.

\subsubsection{Generate a series of hypothetical design projects}

Using the shortlist of factors, their minimum and maximum values and participant's design process (i.e. the Double Diamond), a series of hypothetical design projects (experimental runs) using the Design of Experiments approach (Fisher, 1949) to create specific combinations of factors and levels. These can be generated using statistical software, such as MINITAB 17.0. These design projects should be based on a half-factorial experimental design, an example of which can be seen in Figure 1, as the tasks in the following steps will require significant time and mental effort.

\begin{tabular}{|c|c|c|c|c|c|c|c|c|c|}
\hline \multirow{2}{*}{$\stackrel{\Xi}{\approx}$} & \multicolumn{5}{|c|}{ Factor } & \multicolumn{4}{|c|}{ Design Phase } \\
\hline & 1 & 2 & 3 & 4 & 5 & 1 & 2 & 3 & 4 \\
\hline 1 & Low & Low & Low & Low & High & & & & \\
\hline 2 & High & Low & Low & Low & Low & & & & \\
\hline 3 & Low & High & Low & Low & Low & & & & \\
\hline 4 & High & Low & Low & Low & High & & & & \\
\hline 5 & Low & Low & High & Low & Low & & & & \\
\hline 6 & High & Low & High & Low & High & & & & \\
\hline 7 & Low & High & High & Low & High & & & & \\
\hline 8 & High & High & High & Low & Low & & & & \\
\hline 9 & Low & Low & Low & High & Low & & & & \\
\hline 10 & High & Low & Low & High & High & & & & \\
\hline 11 & Low & High & Low & High & High & & & & \\
\hline 12 & High & Low & Low & High & Low & & & & \\
\hline 13 & Low & Low & High & High & High & & & & \\
\hline 14 & High & Low & High & High & Low & & & & \\
\hline 15 & Low & High & High & High & Low & & & & \\
\hline 16 & High & High & High & High & High & & & & \\
\hline
\end{tabular}

Figure 1. Example of hypothetical design projects described by influential factors \& levels

\subsubsection{Estimate the design effort needed for each hypothetical design project}

Participants should individually, not as a group, estimate the design effort required to complete each hypothetical design project. These estimates should be based exclusively on each participant's experiences and the descriptions provided by the levels of each factor. 


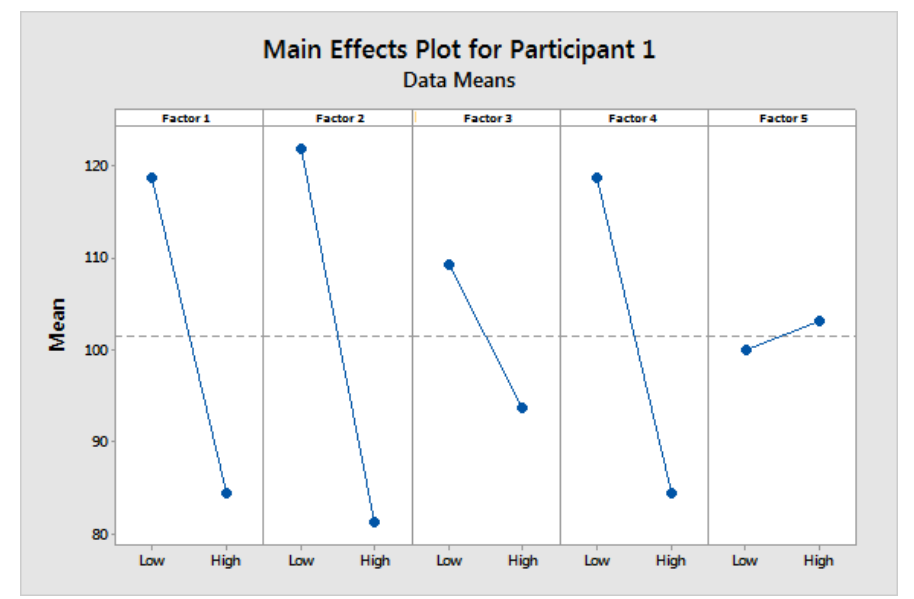

Figure 2. Minitab 17.0 Mean Effects Plot

\subsubsection{Statistical analysis on participant estimates}

The design effort estimates can then be analysed using a statistical software, i.e. MINITAB 17.0, to identify the statistical significance each IF has over design effort. Such software offers insight into the magnitude of such influence and the direction of influence (i.e. a project's length may increase as the value of a given IF decreases). This influence can be determined by the mean effect of each factor at the minimum and maximum level, and shown graphically by the software in mean effect plots, an example of which is shown in Figure 2. From these graphs, it is possible to determine which of the IF's are perceived to have the greatest influence, based on the difference between mean values at the low and high position. The greater the difference, the greater the level of influence.

\section{FUTURE WORK}

In order to determine the utility of such a method, experiments with product design, industrial design and engineering design consultancies should be performed. Through experimentation, it may be possible to identify a number of potential benefits to this method:

\subsection{The visualisation of tacit knowledge}

Tacit knowledge by its very nature can be difficult to articulate. It manifests itself as an instinctual feeling and an individual making a decision based on tacit knowledge may not be able to justify the rationale behind said decision. This proposed method captures their tacit knowledge and graphically represents it. By doing so, it may provide a new level of insight into how an individual designer perceives the design industry and the project planning challenges presented within.

\subsection{Comparison of perceptions}

By generating the same mean plots for each individual participant, it offers an opportunity for direct comparison between said participants. Doing so creates an opportunity to facilitate conversation between said participants, comparing their perceptions and potentially allowing for improved mutual understanding of each participant's perspectives.

\subsection{Factors gathered from multiple sources}

By conducting this proposed method at a number of product design agencies (for example) would potentially allow for the creation of a list design effort level IF's which could contribute towards a wider discussion on the specific factors are exerting influence over design effort level as an industry and observe any trends or changes in the types of factors influencing design effort levels.

\subsection{Optimisation through understanding}

The Design of Experiments method is commonly used for experiment and process optimisation, through the development of regression equations. This optimisation process may extend to this proposed method, allowing design teams to identify which factors to address (by reducing or increasing), to reduce design effort levels, and therefore reduce project cost. 


\section{CONCLUSION}

Understanding which factors are most influential on design effort levels in product design projects will result in improvements in project time estimation by individual design teams, leading to savings and improved efficiencies. In-turn, such understanding at an industry-wide level will lead to improvements in the organisational understanding of product development in general. Current methods typically have two sources of insight: expert opinion, or historical data analysis. Each approach has advantages and disadvantages. The method developed in this paper offers a combination of each approach, utilising the advantages of each approach, while mitigating their disadvantages.

\section{REFERENCES}

Andersson, J., Pohl, J. and Eppinger, S.D. (1998), “A design process modelling approach incorporating nonlinear elements", Proceedings of 1998 DETC: ASME Design Theory and Methodology Conference, Atlanta, Georgia.

Bashir, H.A. and Thomson, V. (1999), “Metrics for design projects: a review”, Design Studies, Vol. 20 No. 3, pp. 263-277.

Bashir, H.A. and Thomson, V. (2001a), "Models for estimating design effort and time", Design Studies, Vol. 22 No. 2, pp. 141-155.

Bashir, H.A. and Thomson, V. (2001b), "An analogy-based model for estimating design effort”, Design Studies, Vol. 22 No. 2, pp. 157-167.

Bashir, H.A. and Thomson, V. (2004), "Estimating design effort for GE hydro projects", Computers \& Industrial Engineering, Vol. 46 No. 2, pp. 195-204.

Benedetto, H., Bernardes, M.M.eS. and Vieira, D. (2018), "Proposed framework for estimating effort in design projects, International Journal of Managing Projects in Business", Emerald, Vol. 11 No. 2, pp. 257-274.

Carrascosa, M., Eppinger, S. and Whitney, D.E. (1998), "Using the Design Structure Matrix to Estimate Product Development Time".

Cho, S.-H. and Eppinger, S.D. (2005), "A simulation-based process model for managing complex design projects", IEEE Transactions on Engineering Management, Vol. 52 No. 3, pp. 316-328.

Dong, C., Horinouchi, T., Nomaguchi, Y. and Fujita, K. (2014), "Design Project Planning Method With Task Option Model and Two-Level Multi-Objective Optimization".

Eckert, C.M. and Clarkson, P.J. (2010), "Planning development processes for complex products", Research in Engineering Design, Vol. 21 No. 3, pp. 153-171.

Eppinger, S.D., Nukala, M.V and Whitney, D.E. (1997), "Generalised models of design interation using signal flow graphs", Research in Engineering Design, Vol. 9 No. 2, pp. 112-123.

Fisher, R.A. (1949), The Design of Experiments, 5th ed., Oliver and Boyd, Edinburgh.

Griffin, A. (1993), "Metrics for measuring product development cycle time", Journal of Product Innovation Management, Vol. 10 No. 2, pp. 112-125.

Griffin, A. (1997), "Modeling and measuring product development cycle time across industries", Journal of Engineering and Technology Management, Vol. 14 No. 1, pp. 1-24.

Harfield, S. (2007), “On design 'problematization': Theorising differences in designed outcomes”, Design Studies, Vol. 28 No. 2, pp. 159-173.

Hellenbrand, D., Helten, K. and Lindemann, U. (2010), “Approach for development cost estimation in early design phases", pp. 779-788.

Holliman, A., Thomson, A. and Hird, A. (2018), "Planning product design \& development: Resourceinfluencing factors based on experience", Proceedings of the 25th International European Operations Management Association (EurOMA) Conference, Budapest, Hungary.

Jack, H. (2013), Chapter 1 - An Overview of Design Projects BT - Engineering Design, Planning, and Management, Academic Press, Boston, pp. 1-32.

Jacome, M.F. and Lapinskii, V. (1997), "NREC: risk assessment and planning of complex designs", IEEE Design \& Test of Computers, Vol. 14 No. 1, pp. 42-49.

Krishnan, V., Eppinger, S.D. and Whitney, D.E. (1995), “Accelerating Product Development by the Exchange of Preliminary Product Design Information”, Journal of Mechanical Design, ASME, Vol. 117 No. 4, pp. 491498.

De Lessio, M.P. (2016), "Planning the product design process", Proceedings of International Design Conference, DESIGN, Vol. DS 84, New York University, 5 MetroTech Center, Brooklyn, NY, United States, pp. 1475-1486.

O'Donovan, B., Eckert, C., Clarkson, J. and Browning, T.R. (2005), "Design planning and modelling", in Clarkson, J. and Eckert, C. (Eds.), Design Process Improvement: A Review of Current Practice, Springer London, London, pp. 60-87. 
Pich, M.T., Loch, C.H. and De Meyer, A. (2002), “On Uncertainty, Ambiguity, and Complexity in Project Management", Management Science, INFORMS, Vol. 48 No. 8, pp. 1008-1023.

Pollmanns, J., Hohnen, T. and Feldhusen, J. (2013), "An Information Model of the Design Process for the Estimation of Product Development Effort BT - Smart Product Engineering”, in Abramovici, M. and Stark, R. (Eds.), Springer Berlin Heidelberg, Berlin, Heidelberg, pp. 885-894.

Saaty, T.L. (1980), The Analytic Hierarchy Process : Planning, Priority Setting, Resource Allocation, McGrawHill International Book Co., New York; London.

Salam, A. and Bhuiyan, N. (2016), "Estimating design effort using parametric models: A case study at Pratt \& Whitney Canada", Concurrent Engineering, SAGE Publications Ltd STM, Vol. 24 No. 2, pp. 129-138.

Salam, A., Bhuiyan, N., Gouw, G.J. and Raza, S.A. (2009), "Estimating design effort for the compressor design department: a case study at Pratt \& Whitney Canada”, Design Studies, Vol. 30 No. 3, pp. 303-319.

Serrat, J., Lumbreras, F. and López, A.M. (2013), "Cost estimation of custom hoses from STL files and CAD drawings", Computers in Industry, Vol. 64 No. 3, pp. 299-309.

Shang, Z.-G. and Yan, H.-S. (2016), "Product Design Time Forecasting by Kernel-Based Regression with Gaussian Distribution Weights", Entropy, available at: https://doi.org/10.3390/e18060231.

Smith, R.P. and Eppinger, S.D. (1997), “A Predictive Model of Sequential Iteration in Engineering Design, Sloan School of Management", Massachusetts Institute of Technology.

Steward, D.V. (1981), "The design structure system: A method for managing the design of complex systems", IEEE Transactions on Engineering Management.

Vapnik, V.N. (1995), The Nature of Statistical Learning Theory, Springer-Verlag New York, Inc.

Wang, Z., Tong, S. and Huang, L. (2015), "Research on the time prediction model of product variant design", 2015 IEEE International Conference on Mechatronics and Automation (ICMA), pp. 572-576.

$\mathrm{Xu}, \mathrm{D}$. and Yan, H.-S. (2006), “An intelligent estimation method for product design time”, The International Journal of Advanced Manufacturing Technology, Vol. 30 No. 7, pp. 601-613.

Xu, D. and Yan, H.S. (2004), "Research on intelligent estimation method for product design time (in Chinese)", Control Decision, Vol. 19 No. 2, pp. 314-318.

Yan, H.-S. and Shang, Z.-G. (2015), "Method for Product Design Time Forecasting Based on Support Vector Regression with Probabilistic Constraints", Applied Artificial Intelligence, Taylor \& Francis, Vol. 29 No. 3, pp. 297-312.

Yan, H., Wang, B., Xu, D. and Wang, Z. (2010), "Computing Completion Time and Optimal Scheduling of Design Activities in Concurrent Product Development Process", IEEE Transactions on Systems, Man, and Cybernetics - Part A: Systems and Humans, Vol. 40 No. 1, pp. 76-89.

Yan, H.S. and Xu, D. (2007), “An Approach to Estimating Product Design Time Based on Fuzzy -nu-Support Vector Machine”, IEEE Transactions on Neural Networks, Vol. 18 No. 3, pp. 721-731.

Yuan, Y.X. and Sun, W.Y. (1997), Optimal Theories and Methods, Science Press, Beijing, China.

Zhigen, S. and Yan, H. (2011), "Forecasting product design time based on Gaussian Margin Regression", IEEE 2011 10th International Conference on Electronic Measurement \& Instruments, Vol. 4, pp. 86-89. 